\title{
Immunohistochemical diagnosis of abdominal and lymph node tuberculosis by detecting Mycobacterium tuberculosis complex specific antigen MPT64
}

\author{
Manju R Purohit 1,2,3, Tehmina Mustafa*1,4, Harald G Wiker ${ }^{4,5}$, \\ Odd Mørkve ${ }^{1,6}$ and Lisbet Sviland ${ }^{1,2}$
}

Address: ${ }^{1}$ Centre for International Health, University of Bergen, Bergen, Norway, ${ }^{2}$ Department of Pathology, Haukeland University Hospital, Bergen, Norway, ${ }^{3}$ Department of Pathology, R.D. Gardi Medical College, Ujjain, India, ${ }^{4}$ Section for Microbiology and Immunology, The Gade Institute, University of Bergen, Norway, ${ }^{5}$ Department of Microbiology and Immunology, Haukeland University Hospital, Bergen, Norway and ${ }^{6}$ Department of Thoracic Medicine, Haukeland University Hospital, Bergen, Norway

Email: Manju R Purohit - manjuraj_purohit@rediffmail.com; Tehmina Mustafa* - Tehmina.Mustafa@cih.uib.no;

Harald G Wiker - Harald.Wiker@gades.uib.no; Odd Mørkve - Odd.Morkve@cih.uib.no; Lisbet Sviland - lisbeth.sviland@helse-bergen.no

* Corresponding author

Published: 25 September 2007

Diagnostic Pathology 2007, 2:36 doi:10.1186/1746-1596-2-36
Received: 7 June 2007

Accepted: 25 September 2007

This article is available from: http://www.diagnosticpathology.org/content/2/I/36

(c) 2007 Purohit et al; licensee BioMed Central Ltd.

This is an Open Access article distributed under the terms of the Creative Commons Attribution License (http://creativecommons.org/licenses/by/2.0), which permits unrestricted use, distribution, and reproduction in any medium, provided the original work is properly cited.

\begin{abstract}
Background: The aim of this study was to evaluate the diagnostic potential of immunohistochemistry using an antibody to the secreted mycobacterial antigen MPT64, in abdominal and lymph node tuberculosis.

Methods: We used formalin-fixed histologically diagnosed abdominal tuberculosis $(n=33)$ and cervical tuberculous lymphadenitis $(n=120)$ biopsies. These were investigated using a combination of Ziehl-Neelsen method, culture, immunohistochemistry with an antibody to MPT64, a specific antigen for Mycobacterium tuberculosis complex organisms. Abdominal and cervical lymph node biopsies from non-mycobacterial diseases $(n=50)$ were similarly tested as negative controls. Immunohistochemistry with commercially available anti-BCG and nested PCR for IS6II0 were done for comparison. Nested PCR was positive in $86.3 \%$ cases and the results of all the tests were compared using nested PCR as the gold standard.
\end{abstract}

Results: In lymph node biopsies, immunohistochemistry with anti-MPT64 was positive in 96 (80\%) cases and 4 (12.5\%) controls and with anti-BCG $92(76.6 \%)$, and $9(28 \%)$ respectively. The results for cases and controls in abdominal biopsies were $25(75.7 \%)$ and 2 (II. I\%) for anti-MPT64 and 25 (75.7\%) and 4 (22\%) for anti-BCG. The overall sensitivity, specificity, positive and negative predictive values of immunohistochemistry with anti-MPT64 was $92 \%, 97 \%, 98 \%$, and $85 \%$, respectively while the corresponding values for anti-BCG were $88 \%, 85 \%, 92 \%$, and $78 \%$.

Conclusion: Immunohistochemistry using anti-MPT64 is a simple and sensitive technique for establishing an early and specific diagnosis of $M$. tuberculosis infection and one that can easily be incorporated into routine histopathology laboratories. 


\section{Background}

Extra-pulmonary tuberculosis (ЕРТВ) accounts for approximately $10-15 \%$ of all tuberculosis infections and occurs in up to $50 \%$ of patients with human immunodeficiency virus (HIV)-tuberculosis co-infection [1-3]. The annual incidence rates of EPTB have increased not only in developing countries but globally over the last few years $[1,2,4]$.

The diagnosis of ЕРТВ has always been problematical. Clinically, the disease presents in protean ways and histological examination is usually required for the diagnosis. Due to overlap of the histological features with other granulomatous conditions, the diagnosis of tuberculosis is dependent on the demonstration of acid fast bacilli (AFB) by Ziehl-Neelsen (ZN) staining. The yield of this method is limited however, in paucibacillary EРTB [5-7] and fresh unfixed tissue with live bacilli is usually not available for culture. Moreover, culture takes several weeks and is often negative in ЕРТВ. There is therefore, a great need for a better diagnostic test to provide an alternative to AFB microscopy and culture.

While, Mycobacterium tuberculosis is the most common causative agent of $\mathrm{EPTB}$, the prevalence of non-tuberculous mycobacteria is increasing with or without HIV infection and ranges from 3.8 to $50 \%$ in different parts of world [7-9]. As treatment is different for the two conditions, it is important to make a definitive diagnosis. However, in areas of the world where the disease is endemic, less than half receives an accurate diagnosis leading to inappropriate empirical treatment [10-12].

Detection of mycobacterial antigens by immunohistochemistry (IHC) using polyclonal and monoclonal antibodies is an alternative to conventional acid-fast staining. A large number of different mycobacterial antigens including BCG, lipoarabinomannan [5,13-17] have been detected with varying results in tissues. These are all common mycobacterial antigens and thus cannot discriminate $M$. tuberculosis from non-tuberculous mycobacteria. However, in a pilot study, we have recently described the high sensitivity and specificity of an in-house rabbit polyclonal antibody in biopsies from patients with tuberculous lymphadenitis to detect a secretory mycobacterial antigen, MPT64, which is present only in M. tuberculosis complex $[14,18]$.

The present study was undertaken to further evaluate the diagnostic potential of immunohistochemial staining to detect MPT64 using a larger sample size from a different population and including other sites. Formalin fixed paraffin embedded biopsies from patients with abdominal tuberculosis and tuberculous lympadenitis were examined and the performance of anti-MPT64 was compared with the commercially available anti-BCG.

\section{Methods}

Histologically diagnosed abdominal tuberculosis $(\mathrm{n}=33)$ and cervical tuberculous lymphadenitis $(n=120)$ biopsies were obtained from the Department of Pathology, Ujjain Hospital, Ujjain, India between July 2004 to March 2006. The diagnostic categories included in the study for cases and controls are shown in table 1. Control biopsies were obtained from the Ujjain Hospital, and also the Department of Pathology, Haukeland University Hospital, Bergen, Norway. Two pulmonary tuberculosis biopsy specimens from the archive with numerous AFB on ZN staining were used as known positive control when required.

Biopsies from patients with pulmonary tuberculosis, on corticosteroids, immunosuppressive therapy were excluded from the study. Detailed clinical history and

Table I: Diagnostic categories of specimens tested.

\begin{tabular}{|c|c|c|c|c|c|}
\hline Diagnosis & Cervical Lymph Nodes & Intestinal wall & Peritoneum & Mesentric Lymph Nodes* & Total number of specimens \\
\hline \multicolumn{6}{|l|}{ CASES } \\
\hline Tuberculosis & 120 & 19 & 9 & 5 & 153 \\
\hline \multicolumn{6}{|l|}{ NEGATIVE CONTROLS } \\
\hline Reactive/Non Specific inflammation & 16 & 0 & 1 & 13 & 30 \\
\hline Foreign body granuloma\# & 10 & 0 & 0 & 0 & 10 \\
\hline Fungal granuloma & 4 & 0 & 0 & 0 & 4 \\
\hline Parasitic granuloma & 0 & 3 & 0 & 0 & 3 \\
\hline Malignancy & 2 & 0 & 1 & 0 & 3 \\
\hline TOTAL & 152 & 22 & 11 & 18 & 203 \\
\hline
\end{tabular}

* no associated intestinal lesion seen.

\# all foreign body granuloma were in skin biopsies. 
examination results were obtained either from the clinical records or from the patients. The majority of lymphadenitis patients presented with a neck mass, while abdominal tuberculosis was mainly associated with abdominal pain. Informed written consent was obtained and the patients were ensured of confidentiality. Ethical approval was obtained from the Institutional ethical committee at Ujjain Hospital and the regional ethical committees in both Norway and India. All the patients were tested for HIV.

\section{Culture, ZN staining \& Histopathology}

One-half of the fresh biopsy specimens were submitted for mycobacterial culture on Lowenstein-Jensen egg media. The other half of the biopsy was fixed by $4 \%$ phosphate buffered formaldehyde for conventional paraffin embedding followed by routine haematoxylin and eosin and $\mathrm{ZN}$ stain to detect AFB. ZN staining was performed by heat carbol fuchsin method.

For histopathology, the sections were examined for the presence of granulomas and subdivided into two groups for analysis. Well-organized granulomas were characterized by a central group of epitheloid histiocytes, Langhan's giant cells, a mantle of lymphocytes and fibrous tissue. Poorly-organized granulomas showed a diffuse mixture of lymphocytes, histiocytes, and plasma cells with occasional giant cells. Each granuloma was also analyzed for the presence or absence of necrosis. The number of granulomas per sections, their type of organization and presence of necrosis was noted.

\section{Immunohistochemistry}

IHC was performed using the DakoCytomation kit (EnVision + System-HRP; DakoCytomation Denmark A/S, Glostrup, Denmark). Tissue sections were deparaffinized, hydrated, and after microwave antigen retrieval, the endogenous peroxidase activity was inhibited by incubating the sections with hydrogen peroxide for 8 minutes. The slides were then treated with primary antibodies - (i) anti-BCG, (DAKO, Hamburg, Germany) at 1/5000 dilution for 1 hour after treating sections with 3\% bovine serum albumin for 3 minutes, (ii) in-house absorbed polyclonal anti-MPT64 antibody at $1 / 250$ dilution for 1 hour. Optimal dilutions were determined prior to these experiments. Sections were incubated with anti-rabbit dextran polymer conjugated to horseradish peroxidase for 45 minutes (30 minutes for anti-BCG). Antigen was visualized with 3-amino-9-ethylcarbazol- and hydrogen peroxide containing substrate and counter-stained with haematoxylin. All incubations were carried out at room temperature and the sections were thoroughly washed inbetween incubations. In every experiment, one positive control and two negative controls were included. In one negative control primary antibody was substituted with antibody diluent and the other was with an irrelevant rabbit polyclonal antibody.

Mycobacterial antigen load was evaluated by counting the stained cells with light microscopy using a $40 \times$ ocular fitted with a $10 \times 10 \mathrm{~mm}$ graticule and by evaluation of the staining intensity. For each section, three granulomas were selected for analysis. The number of stained epitheloid cells, stained giant cells and the total number of nucleated cells were counted for each granuloma and the results were presented as percentage of stained cells. The intensity of staining of section was evaluated separately and categorized as weak, moderate, and strong staining based on subjective assessment.

\section{Nested Polymerase Chain Reaction for IS6IIO}

Five to six, $8 \mu \mathrm{m}$ sections from each paraffin embedded tissue blocks were collected in sample preparation tubes for nested PCR. Carry-over tissue contamination was prevented by cleaning the blade with $96 \%$ ethanol after sectioning each sample; negative controls were sectioned first, followed by test blocks and positive control blocks.

DNA extraction and nested PCR on paraffin sections were performed as described previously [14]. Briefly, following proteinase $\mathrm{K}$ digestion, bacterial genomic DNA was eluted in water using a MagAttract DNA mini M48 Kit (Qiagen, West Sussex, UK) on Biorobot M48 (Qiagen). A 123-base pair fragment from IS6110 was amplified using the following primers 5' CCTGCGAGCGTAGGCGTCGG 3' and 5' CTCGTCCAGCGCCGCTTCGG 3'. The product was subjected to a second round of PCR amplification using the primers $5^{\prime}$ TTCGGACCACCAGCACCTAA $3^{\prime}$ and 5' TCGGTGACAAAGGCCACGTA 3 ' to amplify a 92-base pair fragment. The PCR reaction mixture consisted of $5 \mu \mathrm{l}$ eluted DNA, $25 \mu \mathrm{l}$ of HotStarTaq master mix (Qiagen), $0.25 \mu \mathrm{l}$ of each $100 \mu \mathrm{M}$ primer stock solution, distilled water to make a final volume of $50 \mu \mathrm{l}$. For nested PCR, 1 $\mu \mathrm{l}$ of the first PCR product was used as template. The reaction cycle for the first PCR was $-94^{\circ} \mathrm{C}$ for 1 minute, $68^{\circ} \mathrm{C}$ for 1 minute, $72^{\circ} \mathrm{C}$ for 20 seconds for 45 cycles and for the nested PCR $-94^{\circ} \mathrm{C}$ for 1 minute, $58^{\circ} \mathrm{C}$ for 1 minute, $72^{\circ} \mathrm{C}$ for 20 seconds for 35 cycles. Both PCR's had an initial heat activation step of $95^{\circ} \mathrm{C}$ for 15 minutes and a final extension of $72^{\circ} \mathrm{C}$ for 10 minutes. The amplified product was analyzed in a 3\% agarose gel stained with ethidium bromide. Mycobacterial DNA, and positive PCR product were included as positive controls and an extraction control (with all the steps but without any tissue), a reaction tube with substitution of distilled water for the test template and a sample which previously yielded negative result on PCR were included as negative control in each PCR run. 


\section{Data Analysis}

Data entry and analysis was done using SPSS 12.0 for Windows. Pearsons chi-square test was used to determine the significance among categorical variables. Non-parametric tests were used for two-group comparisons. Differences were considered statistically significant if $\mathrm{p} \leq 0.05$. The diagnostic indices were calculated by decision matrix comparison.

\section{Results}

A total of 203 biopsy specimens were studied. All the patients were negative for HIV.

\section{Acid-Fast Bacilli microscopy and Culture (table 2)}

Acid fast bacilli were detected by ZN staining of abdominal and lymph node biopsies in 0/33 (0\%) and 14/120 (11.7\%) specimens respectively. Mycobacterium was isolated on culture from $4 / 33(12.1 \%)$ and $27 / 117$ (23\%) specimens of abdominal and lymph node cases respectively. Culture results were not available from 3 cases and 24 controls. None of the control biopsies showed positive result for either of the tests.

\section{Histopathology}

Both well-organized and poorly-organized granulomas were observed in biopsies from abdominal and lymph node cases. In abdominal tuberculosis, all the mesenteric lymph nodes showed well-organized necrotic granulomas and in intestinal wall, necrotic granulomas were seen in $58 \%$ of the cases while other cases had non-necrotic granulomas with or without fibrosis.

Lymph nodes showed typical well-organized granulomas in $70 \%$ of cases, mixed in $18 \%$ and poorly-organized in $12 \%$ of cases. Ninety percent of cases showed necrosis, however, both necrotic and non-necrotic granulomas were often seen in the same section.

\section{Immunohistochemistry}

IHC with anti-MPT64 was positive in 14 (73.7\%), 7 $(77.7 \%)$ and $4(80 \%)$ cases from intestinal wall, peritoneum, and mesenteric lymph node respectively and 2 (11\%) controls. Similarly, the corresponding results for anti-BCG were 15 (78.9\%), 6 (66\%), 4 (80\%) respectively for cases and $4(22 \%)$ for controls (Table 2). In lymph node biopsies, IHC with anti-MPT64 was positive in 96 (80\%) cases and $4(12.5 \%)$ controls whereas anti-BCG was positive in 92 (76.6\%) cases, and 9 (28.1\%) controls.

A comparison of the two antibodies looking at percentage of stained cells, and intensity of staining in relation to necrosis and organization of granulomas is shown in table 3 and figures 1 and 2 . In the well-organized granulomas, the percentage of stained cells $(\mathrm{p}=0 \cdot 04)$ and the intensity of staining ( +2 or +3 ; $\mathrm{p}=0.001)$ was significantly higher for anti-MPT64 than anti-BCG. No significant difference of staining percentage or intensity was detected between the two antibodies in poorly-organized granulomas. In non-necrotic granuloma the percentage of positive cells $(p=0.02)$ and the intensity of staining $(p=0.03)$ was significantly higher with anti-MPT64 than with antiBCG. In the necrotic granulomas, the intensity of staining with anti-MPT64 was higher but there was no significant difference between the percentages of stained cells between the two antibodies.

The location and pattern of expression of the two antibodies varied. Staining with anti-MPT64 was seen mainly in the inflammatory cells. The necrotic centres were generally negative, except in $8 \%$ of necrotic granulomas where occasional but strong signals were detected. Staining pattern was predominantly granular with anti-MPT64. With anti-BCG, positive signals were detected both in the necrotic centre and in inflammatory cells in all the necrotic granulomas. Unlike anti-MPT64, the staining pattern with anti-BCG was predominantly diffuse (fig. 2, 3).

Table 2: Positive results of different diagnostic procedure on cervical lymph nodes and abdominal biopsies.

\begin{tabular}{|c|c|c|c|c|c|c|c|c|}
\hline \multirow[t]{3}{*}{ Diagnostic Procedure } & \multicolumn{2}{|c|}{$\begin{array}{l}\text { Cervical Lymph Nodes Biopsy } \\
\qquad(\mathrm{n}=152)\end{array}$} & \multicolumn{6}{|c|}{ Abdominal biopsy $(n=5 I)$} \\
\hline & \multirow[b]{2}{*}{$\begin{array}{c}\text { Case } \\
(\mathrm{n}=120) \\
n(\%)\end{array}$} & \multirow[b]{2}{*}{$\begin{array}{c}\text { Control } \\
(n=32) \\
n(\%)\end{array}$} & \multicolumn{2}{|c|}{ Intestinal wall } & \multicolumn{2}{|c|}{ Peritoneum } & \multicolumn{2}{|c|}{ Mesenteric Lymph Nodes } \\
\hline & & & $\begin{array}{c}\text { Case } \\
(\mathrm{n}=19) \\
\mathrm{n}(\%)\end{array}$ & $\begin{array}{c}\text { Control } \\
(n=3) \\
n(\%)\end{array}$ & $\begin{array}{c}\text { Case } \\
(n=9) \\
n(\%)\end{array}$ & $\begin{array}{c}\text { Control } \\
(n=2) \\
n(\%)\end{array}$ & $\begin{array}{c}\text { Case } \\
(n=5) \\
n(\%)\end{array}$ & $\begin{array}{c}\text { Control } \\
(n=13) \\
n(\%)\end{array}$ \\
\hline ZN stain & $14(1 \mid .6)$ & 0 & 0 & 0 & 0 & 0 & 0 & 0 \\
\hline LJ Culture & $27(22.5)$ & 0 & 0 & 0 & $2(22)$ & 0 & $2(40)$ & 0 \\
\hline Anti-BCG & $92(76.6)$ & $9(28)$ & $15(78.9)$ & $\mathrm{I}(33)$ & $6(66)$ & $\mathrm{I}(50)$ & $4(80)$ & $2(15.4)$ \\
\hline Anti-MPT64 & $96(80)$ & $4(12.5)$ & |4(73.7) & 0 & $7(77.7)$ & $\mathrm{I}(50)$ & $4(80)$ & $\mathrm{I}(7.7)$ \\
\hline PCR & $104(86.6)$ & $3(9.4)$ & 17(89) & 0 & $7(77.7)$ & 0 & $4(80)$ & $\mathrm{I}(7.7)$ \\
\hline
\end{tabular}


Table 3: Intensity of immunohistochemical staining by two antibodies in relation to granuloma features.

\begin{tabular}{|c|c|c|c|c|c|c|}
\hline \multirow[t]{2}{*}{ Granuloma characteristics } & \multicolumn{3}{|c|}{ Intensity of anti-BCG staining } & \multicolumn{3}{|c|}{ Intensity of anti-MPT64 staining } \\
\hline & Mild & Moderate & Strong & Mild & Moderate & Strong \\
\hline \multicolumn{7}{|l|}{ Organization } \\
\hline Well Organised & $46^{*}$ & 38 & 9 & 8 & $51 * *$ & 34 \\
\hline Non Organised & 28 & 8 & 1 & 13 & 14 & 10 \\
\hline \multicolumn{7}{|l|}{ Necrosis } \\
\hline Non Necrotic & 30 & 23 & 4 & 4 & 29 & 24 \\
\hline Necrotic & 44 & 23 & 6 & 17 & $36 * * *$ & 20 \\
\hline
\end{tabular}

$*_{p}=.02, *^{*} \mathrm{p}=.001, *^{*} *_{\mathrm{p}}=.026$

The performance of the two antibodies in giant cells was assessed separately. Unlike the epithelioid cells, there was no significant difference in the percentage of giant cells stained with either of the antibodies. However, the intensity of staining for anti-BCG in the giant cells was weak compared to anti-MPT64 (fig. 2C, 2F).

\section{Polymerase Chain Reaction}

The results of IS6110 PCR assay is shown in table 2. Overall PCR assay positivity was 132/153(86.6\%) in histologcally diagnosed tuberculosis cases. Among these, eight cases were positive after the first PCR amplification while the majority ( $\mathrm{n}=124$ ) were positive on nested PCR only. Cases which were positive with first PCR run had higher percentage of anti-MPT64 stained cells. All the positive controls were positive on both first PCR run and nested PCR.

\section{Comparison and validation of the result of various tests}

The results of various tests were compared using nested PCR as the gold standard. All ZN and culture positive cases were positive for anti-MPT64, anti-BCG and PCR while $\mathrm{ZN}$ was positive in only 14 culture positive cases. With IHC using anti-MPT64 and anti-BCG positive results

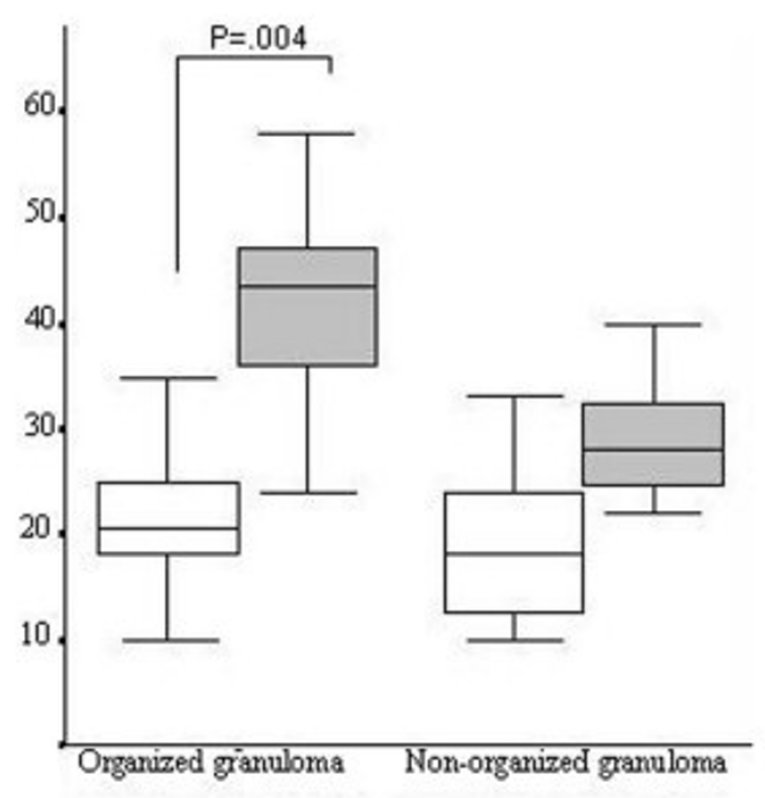

Percentage of cells stained with anti-BCG

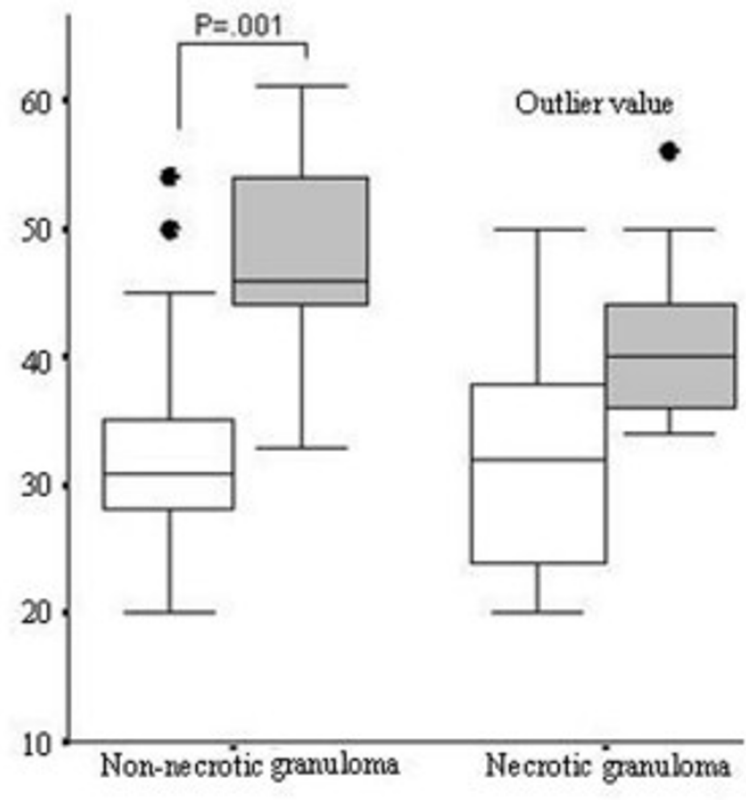

Percentage of cells stained with anti-MPT64

\section{Figure I}

A: Percentage of stained cells by two antibodies in relation to organization of granuloma. B: Percentage of stained cells by two antibodies in relation to necrosis in granuloma. 

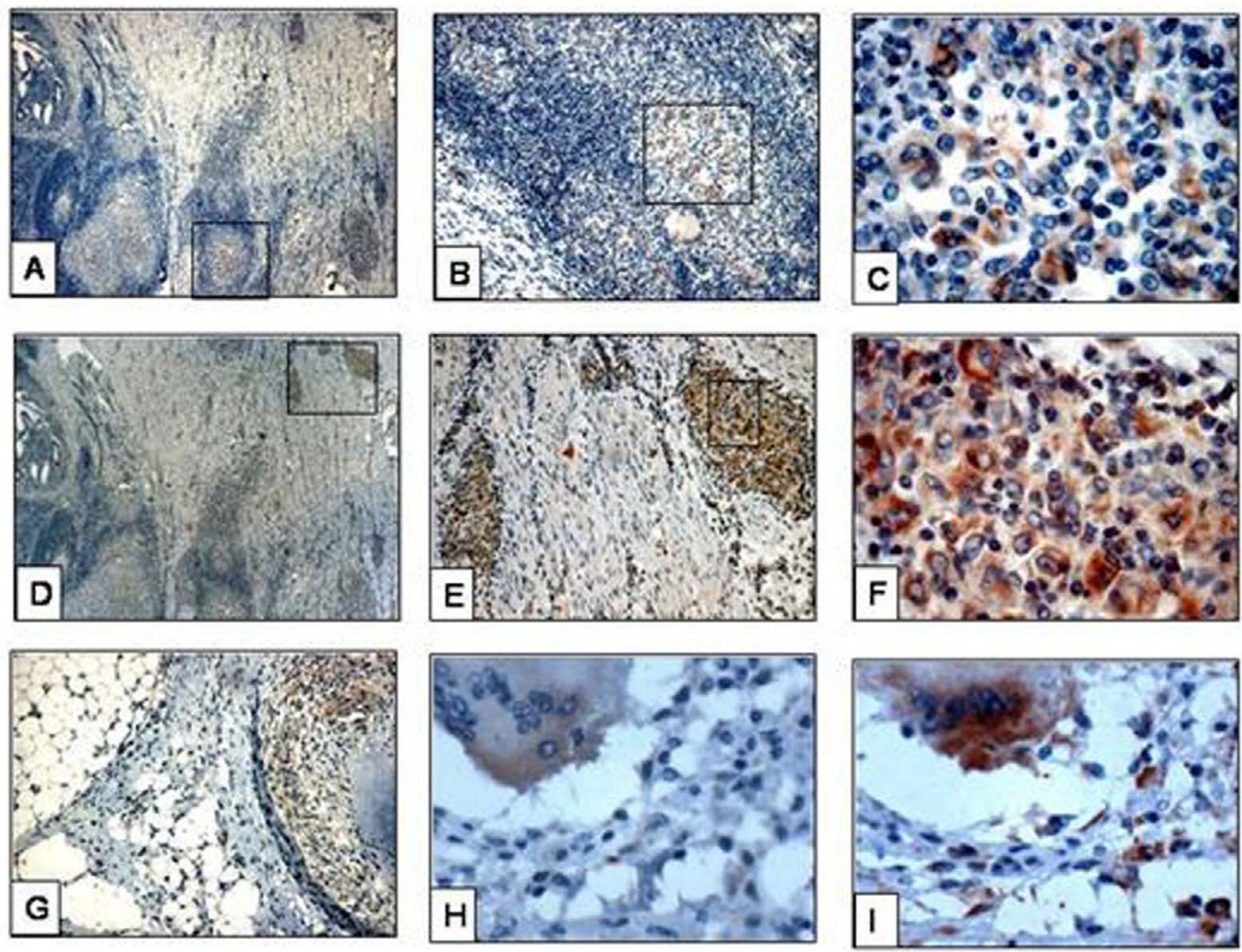

Figure 2

Immunohistochemical staining in abdominal tuberculosis. A-C : Staining by anti-BCG in granuloma in intestinal wall, D-F : staining by anti-MPT64 in granuloma in intestinal wall. The area in square is magnified in subsequent sections, G : staining by anti-BCG in granuloma in peritoneum, $\mathrm{H}$ : diffuse staining of giant cells in peritoneum by anti-BCG, I: same giant cell as shown in $\mathrm{H}$ showing strong, granular staining with anti-MPT64.

were found in 125 and 120 specimens respectively with a sensitivity of more than $85 \%$ by both antibodies (table 4 ). Of 67 PCR negative cases, anti-MPT64 and anti-BCG were negative in 65 and 57 respectively, thus giving a specificity of $93 \%$ for anti-MPT64 and 88\% for anti-BCG (table 4 ). Overall comparison showed significant differences in the sensitivity of IHC compared with sensitivity of $\mathrm{ZN}$ staining and culture $(\mathrm{p}=<0.001)$. No significant difference was found in the specificity of IHC when compared with the other tests. The proportion agreement between PCR and anti-MPT64 was 93\% (kappa-0.85).

\section{Comparison between Cervical Lymph Node and Abdominal Tissue Samples for various tests}

In tuberculous lymphadenitis the sensitivity of $\mathrm{ZN}$ staining (13\%) and culture (25\%) was higher than in abdominal tuberculosis ( $0 \%$ and $12.5 \%$ respectively). The sensitivity of IHC with both the antibodies was high and there was no significant difference between cervical tuberculous lymph nodes and different sites of abdominal tuberculosis. The specificity of anti-BCG was, however, $60 \%$ in intestinal wall compared to $86 \%$ and $92.3 \%$ in cervical lymph nodes and mesenteric lymph nodes respectively. In contrast, specificity with MPT64 was very high and was found to be $100 \%$ in intestinal wall and mesenteric lymph nodes and $98 \%$ in cervical lymph nodes (table 4 ). 

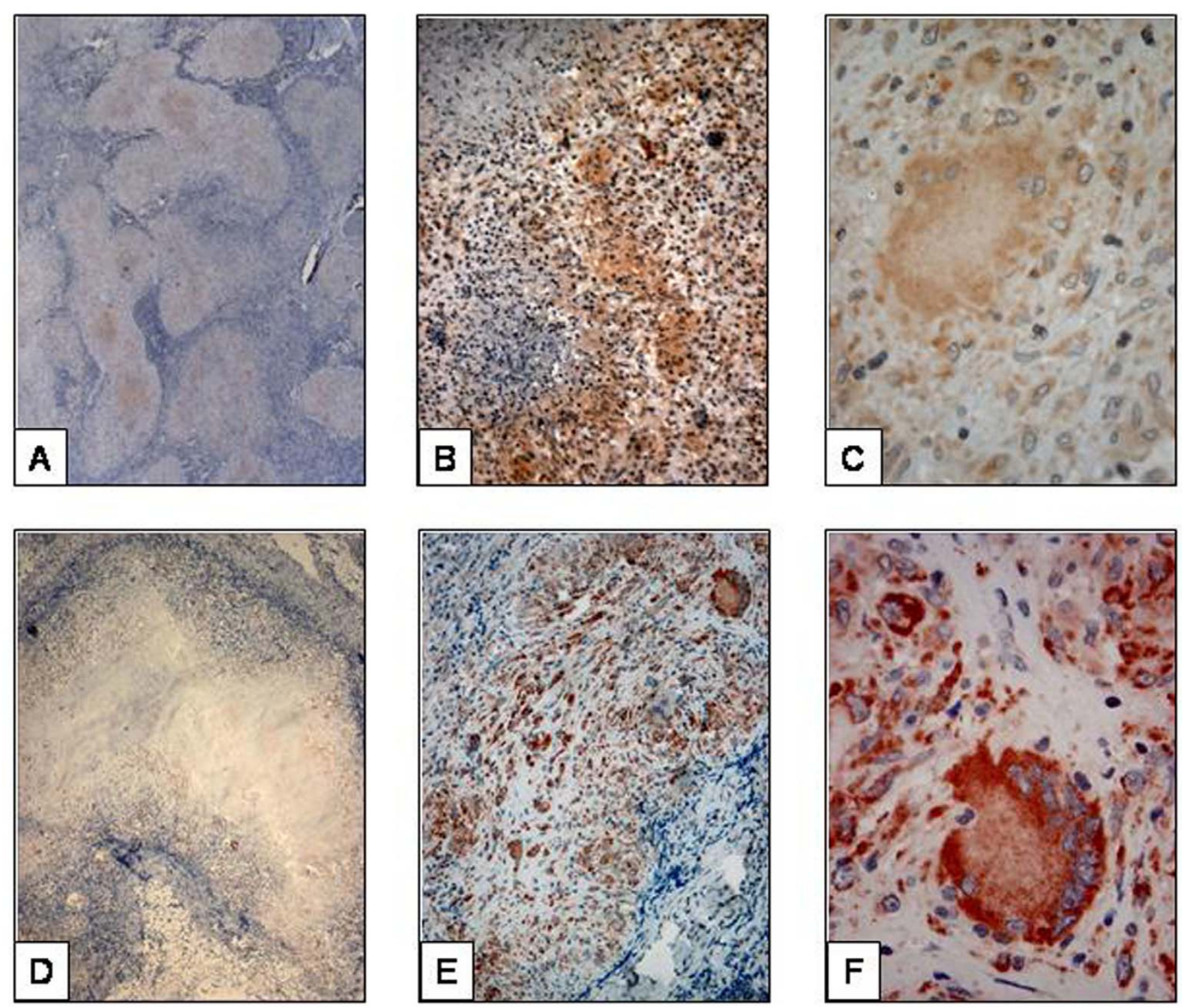

Figure 3

Immunohistocheminal staining of lymph node tuberculosis. A : Staining by anti-BCG in organized granuloma. The central necrotic area is also showing staining, B : staining by anti-BCG in poorly organized granuloma. There is diffuse staining with background staining, $C$ : The diffuse and weak staining of giant cell by anti-BCG, $D$ : staining by anti-MPT64 in organized granuloma. The central necrotic area is not showing staining, $E$ : staining by anti-MPT64 in poorly organized granuloma. There is granular staining in clear background, $\mathrm{F}$ : The strong and granular staining of giant cell by anti-MPT64.

\section{Discussion}

There have been several reports describing the use of IHC in the diagnosis of tuberculosis (14). However, in this study we show that using an antigen against the secretory mycobacterial antigen MPT64, it is possible to achieve consistently high sensitivity (89-93\%) and specificity (95$98 \%$ ) with IHC on different types of tissues. The strength of this technology is that it is robust, readily available in routine surgical pathology laboratories and can detect fragmented tubercle bacilli [19]. Compared with ZN staining that has a sensitivity of $10-45 \%$ [19] and requires an intact cell wall this technique offers a major improvement in diagnostic potential and should be suited for the diagnosis of pauci-bacillary EPTB. IHC for tuberculosis has, however, been slow to catch on as a routine diagnostic method in histopathology laboratories probably due to the lack of a specific anti-mycobacterial antibody suitable for all types of tissue $[5,14,16]$ and hence the exact diagnostic role of IHC for $M$. tuberculosis has to be assessed in appropriate control groups and with appropriate antisera in endemic areas. Our large study is the first to show that IHC with an antibody to MPT64 is sufficiently robust 
Table 4: Diagnostic validation of different tests using nested PCR as gold standard (all values are in percentage).

\begin{tabular}{lcccc}
\hline Diagnostic method & Sensitivity & Specificity & PPV & NPV \\
\hline LYMPH GLAND TB & & & & \\
Anti-BCG & 88 & 86 & 94 & 76 \\
Anti-MPT64 & 93 & 98 & 99 & 85 \\
\hline ABDOMINAL TB & & & & \\
Anti-BCG & 86 & 81 & 86 & 81 \\
Anti-MPT64 & 89 & 95 & 96 & 87 \\
\hline TOTAL TB CASES & & & & \\
Anti-BCG & 88 & 85 & 92 & 78 \\
Anti-MPT64 & 92 & 97 & 98 & 85 \\
\hline
\end{tabular}

$\mathrm{PPV}=$ positive predictive value, $\mathrm{NPV}=$ negative predictive value

to establish etiological diagnosis of M. tuberculosis complex infection in different types of tissues of EPTB.

Our results show that IHC with anti-MPT64 has better specificity, sensitivity, and predictive values than antiBCG (table 4). This was particularly clear in intestinal wall tuberculosis, where anti-MPT64 showed a $100 \%$ specificity compared with $60 \%$ for anti-BCG (table 3 ). AntiMPT64 antibodies also gave sharp and strong signals with clear background compared with anti-BCG antibodies making interpretation easier and permitting a more confident diagnosis of $M$. tuberculosis complex organism. Lower specificity with anti-BCG could be due to cross-reactivity with other infectious organisms as described earlier [2022].

The sensitivity of anti-MPT64 is also very high but not very different from anti-BCG. The amplification method used in IHC improves the recognition of positive fragments. The few false negatives could be caused by the length of formalin fixation prior to processing which is known to reduce sensitivity[23]. Another explanation for the false negative results may be that the number of mycobacteria present is below the sensitivity level of IHC (about $5 \times 10^{5}$ to $1 \times 10^{6}$ organisms per gram tissue) and the lesions are exuberant inflammatory responses to a minimal number of organisms[24].

Four of the negative controls were positive with both PCR and IHC with both antibodies. Among these were two lymph node samples with histological changes of nonspecific lymphadenitis that may represent early or latent tuberculosis infection. According to Goel et al [25], early tuberculous lesions may not be identified by histopathology because the formation of granulomas and emergence of the classical histopathological tuberculous picture may be a late phenomenon. They suggest that such cases might represent the transition between the incubation and development of disease[25]. Perhaps, in some cases, our IHC method can play a role in the early diagnosis of tuberculosis when histological examination fails to provide a diagnosis. The high prevalence of tuberculosis together with parasitic infection is well known in tuberculosis endemic countries. One of our controls with intestinal parasite turned out positive with IHC and PCR [26] and may well be a case of tuberculosis. It is difficult to explain the positive results of both tests on foreign body granulomas from Norway, however, as suggested by Mustafa et al, the possibility of latent infection cannot be ruled out [14].

In endemic countries, the majority of granulomatous lesions without necrosis are considered to be tuberculosis but this may not be the case in the developed world. Interestingly, when we looked specifically for the bacilli in the different zones of the granuloma they were more frequently detected by anti-MPT64 in the epitheloid cells than in the necrotic area. Using anti-BCG antibodies antigens were also detected in necrotic area. We also found that the percentage of stained cells was higher in nonnecrotic granulomas than in necrotic granuloma with anti-MPT64 compared to anti-BCG with clearer and stronger signals. Hence, non-necrotic granulomatous lesion staining with MPT64 will support a diagnosis of tuberculosis.

Ideally, culture should be used as gold standard when comparing diagnostic test performance in tuberculosis. This investigation is, however, associated with low sensitivity especially in ЕРТВ and as in our series, the corresponding results from controls are usually not available [27]. Histopathology remains one of the most important methods for diagnosing tuberculosis, however; it cannot differentiate changes caused by M. tuberculosis, non-tuberculous mycobacteria or other granulomatous diseases. We used nested PCR as the reference for comparison. In recent years, the sensitivity and specificity of PCR for diagnosis of tuberculosis has been well documented and is in the range of $60-98 \%$ in reported series where PCR was compared with culture as gold standard $[28,29]$. Our results also showed strong association between PCR and culture with all culture positive samples also being PCR positive. While PCR is increasingly used in the detection of mycobacteria from the tissue sample, the cost of the instruments and reagents, sensitivity to contamination and technical demand limits its use in developing countries [30].

\section{Conclusion}

We have shown that IHC with an antibody to MPT64, a secreted antigen specific to the $M$. tuberculosis complex, is a specific and sensitive technique for diagnosis of EPTB. It is a cheap, robust and rapid method that can be used in a routine laboratory to provide a result in one working day and ensures the early institution of therapy. Being specific, 
anti-MPT64 would be of value in differentiating M. tuberculosis from other organisms, especially non-tuberculous mycobacteria, and other granulomatous inflammations.

\section{Competing interests}

The author(s) declare that they have no competing interests.

\section{Authors' contributions}

MRP, TM and LS designed the study, drafted the manuscript, and were also involved in the subject enrolment. MRP performed the experiments and data acquisition and analysis. All authors contributed, read and approved the final draft.

\section{Acknowledgements}

We are grateful to Dr V.K. Mahadik, Director of R.D. Gardi Medical College for his encouragement and support during this work. We are thankful to all laboratory technicians of Ujjain hospital for their support in data collection and Gerd Lillian Hallseth and Randi L. Nygaard for technical guidance. We gratefully acknowledge Prof. Laurence Albert Bindoff for his constructive comments and language correction. State Education Loan Fund, Norway and Helse-Vest and Norwegian trusts for research-funding funded this study.

\section{References}

I. Small PM, Schecter GF, Goodman PC, Sande MA, Chaisson RE, Hopewell PC: Treatment of tuberculosis in patients with advanced human immunodeficiency virus infection. $N$ Engl J Med I99I, 324(5):289-294.

2. Clark RA, Blakley SL, Greer D, Smith MH, Brandon W, Wisniewski TL: Hematogenous dissemination of Mycobacterium tuberculosis in patients with AIDS. Rev Infect Dis |991, 13(6): 1089-1092.

3. Seibert AF, Haynes J Jr., Middleton R, Bass JB Jr.: Tuberculous pleural effusion. Twenty-year experience. Chest 1991, 99(4):883-886.

4. Galkin VB, lagafarova RK, Khokkanen VM, Grashchenkova OV: [Epidemiological and clinical aspects of extrapulmonary tuberculosis in North-Western Russia]. Probl Tuberk 1998:36-38.

5. Ulrichs T, Lefmann M, Reich M, Morawietz L, Roth A, Brinkmann V, Kosmiadi GA, Seiler P, Aichele P, Hahn H, Krenn V, Gobel UB, Kaufmann $\mathrm{SH}$ : Modified immunohistological staining allows detection of Ziehl-Neelsen-negative Mycobacterium tuberculosis organisms and their precise localization in human tissue. J Pathol 2005, 205(5):633-640.

6. Perkins MD, Roscigno G, Zumla A: Progress towards improved tuberculosis diagnostics for developing countries. Lancet 2006, 367(95 I 4):942-943.

7. Mfinanga SG, Morkve O, Kazwala RR, Cleaveland S, Sharp MJ, Kunda J. Nilsen R: Mycobacterial adenitis: role of Mycobacterium bovis, non-tuberculous mycobacteria, HIV infection, and risk factors in Arusha, Tanzania. East Afr Med J 2004, 8 I (4): I II- 178.

8. Jindal N, Devi B, Aggarwal A: Mycobacterial cervical lymphadenitis in childhood. Indian J Med Sci 2003, 57(I):12-15.

9. Evans MJ, Smith NM, Thornton CM, Youngson GG, Gray ES: Atypical mycobacterial lymphadenitis in childhood--a clinicopathological study of 17 cases. J Clin Pathol 1998, 5 I ( I 2):925-927.

10. Mfinanga SG, Morkve O, Sviland L, Kazwala RR, Chande H, Nilsen R: Patient knowledge, practices and challenges to health care system in early diagnosis of mycobacterial adenitis. East Afr Med J 2005, 82(4): 173-180.

II. Aggarwal P, Wali JP, Singh S, Handa R, Wig N, Biswas A: A clinicobacteriological study of peripheral tuberculous lymphadenitis. J Assoc Physicians India 2001, 49:808-812.

12. Udwadia ZF: Controlling tuberculosis in India. N Engl J Med 2003, 348(8):758-9; author reply 758-9.
13. Furak J, Trojan I, Szoke T, Tiszlavicz L, Boda K, Balogh A, Roth E: [Histological and immunohistochemical structure of pulmonary tuberculotic granulomas in untreated cases and cases treated with antitubercular drugs]. Orv Hetil 2003, I 44(27): I $347-$ I 352.

14. Mustafa T, Wiker HG, Mfinanga SG, Morkve O, Sviland L: Immunohistochemistry using a Mycobacterium tuberculosis complex specific antibody for improved diagnosis of tuberculous lymphadenitis. Mod Pathol 2006, I9(12):1606-1614.

15. Mustafa T, Phyu S, Nilsen R, Jonsson R, Bjune G: A mouse model for slowly progressive primary tuberculosis. Scand J Immunol 1999, 50(2): $127-136$.

16. Sumi MG, Mathai A, Reuben S, Sarada C, Radhakrishnan VV: Immunocytochemical method for early laboratory diagnosis of tuberculous meningitis. Clin Diagn Lab Immunol 2002, 9(2):344-347.

17. Barbolini G, Bisetti A, Colizzi V, Damiani G, Migaldi M, Vismara D: Immunohistologic analysis of mycobacterial antigens by monoclonal antibodies in tuberculosis and mycobacteriosis. Hum Pathol 1989, 20(I I): 1078-1083.

18. Nagai S, Wiker HG, Harboe M, Kinomoto M: Isolation and partial characterization of major protein antigens in the culture fluid of Mycobacterium tuberculosis. Infect Immun 1991, 59(1):372-382.

19. Gutierrez CMM Garcia M, J,F: Comparison of Ziehl-Neelsen staining and immunohistochemistry for detection of Mycobacterium bovis in bovine and caprine tuberculosis lesions. J Comp Pathol 1993, 109: 361-370.

20. Arrese JE, Pierard GE: Immunostaining of various micro-organisms by a polyclonal anti-Mycobacterium bovis antibody. J Am Acad Dermatol 1998, 39(5 Pt I):810.

21. Kutzner H, Argenyi ZB, Requena L, Rutten A, Hugel H: A new application of $B C G$ antibody for rapid screening of various tissue microorganisms. J Am Acad Dermatol 1998, 38(I):56-60.

22. Closs $\mathrm{O}$, Harboe M, Axelsen NH, Bunch-Christensen K, Magnusson $M$ : The antigens of Mycobacterium bovis, strain BCG, studied by crossed immunoelectrophoresis: a reference system. Scand J Immunol 1980, I 2(3):249-263.

23. Haines DM, Chelack BJ: Technical considerations for developing enzyme immunohistochemical staining procedures on formalin-fixed paraffin-embedded tissues for diagnostic pathology. J Vet Diagn Invest I99I, 3(1): I0I-I I 2.

24. Kobayashi K, Blaser MJ, Brown WR: Immunohistochemical examination for mycobacteria in intestinal tissues from patients with Crohn's disease. Gastroenterology 1989, 96(4): $1009-1015$.

25. Goel MM, Ranjan V, Dhole TN, Srivastava AN, Mehrotra A, Kushwaha MR, Jain A: Polymerase chain reaction vs. conventional diagnosis in fine needle aspirates of tuberculous lymph nodes. Acta Cytol 200I, 45(3):333-340.

26. Borkow G, Weisman Z, Leng Q, Stein M, Kalinkovich A, Wolday D, Bentwich Z: Helminths, human immunodeficiency virus and tuberculosis. Scand J Infect Dis 200I, 33(8):568-57I.

27. Li JYWMS, Lo STHMS, Ng CSFRCP: Molecular Detection of Mycobacterium tuberculosis in Tissues Showing Granulomatous Inflammation Without Demonstrable Acid-Fast Bacilli. [Article]. Diagnostic Molecular Pathology June 2000;9(2):67-74.

28. Cheng VC, Yam WC, Hung IF, Woo PC, Lau SK, Tang BS, Yuen KY: Clinical evaluation of the polymerase chain reaction for the rapid diagnosis of tuberculosis. J Clin Pathol 2004, 57(3):28I-285.

29. Azov AG, Koch J, Hamilton-Dutoit SJ: Improved diagnosis of mycobacterial infections in formalin-fixed and paraffinembedded sections with nested polymerase chain reaction. Apmis 2005, I I 3(9):586-593.

30. Sumi MG, Mathai A, Sheela R, Radhakrishnan NS, Radhakrishnan VV, Indhulekshmy R, Mundayoor S: Diagnostic utility of polymerase chain reaction and immunohistochemical techniques for the laboratory diagnosis of intracranial tuberculoma. Clin Neuropathol 200I, 20(4): I76-I80. 